\title{
Media optimization for increased yield of glycerol using various substrates
}

\author{
Jaya Barath J.*, Asma Musfira S., Giridhar R., Arulmurugan R., Shyam Sundar S. and \\ Shanmuga Gowtham J. \\ *Department of Biotechnology, Pavendar Bharathidasan College of Engineering and Technology, Thanjai \\ Natrajan Nagar, Mathur, Tiruchirappalli- 620 024, TamilNadu
}

\begin{abstract}
Glycerol finds a lot of industrial applications in the fields of cosmetics pharmaceuticals and in industries. In the present study the production of glycerol is studied using Candida krusei in a batch reactor. The influence of different carbon source on glycerol production is studied using glucose, sucrose and different combinations of glucose and sucrose mixtures. The effect of initial $\mathrm{pH}$ was studied by varying the initial $\mathrm{pH}$ from 5.0 to 9.0 in order to find the optimum pH to maximize the concentration of cellmass and glycerol. Initial $\mathrm{pH} 7.0$ was found to be an optimum for glycerol fermentation. The maximum glycerol concentration $(0.58 \mathrm{~g} / \mathrm{l})$ was obtained when glucose is used as a carbon source at a concentration of $200 \mathrm{~g} / \mathrm{l}$.
\end{abstract}

Keywords: Glycerol, Glucose, optimization

\section{Introduction}

Glycerol was first discovered by Swedish scientist Scheele CW by heating several oils and fats with lead oxide. Of all the properties known of glycerol it's a colourless odourless liquid of syrupy consistence with sweet taste. It is hygroscopic miscible with water and alcohol but insoluble in ether chlorinated solvents hydrocarbon and oils. Glycerol itself has solvent properties; it is non-toxic and easily biodegradable. Glycerol is an important chemical with many uses including its use for producing 1,3-propanediol by fermentation. It can be produced from renewable resources by fermentation. Due to poor yields and productivity, the old sulphite process for glycerol production has been gradually replaced by using osmophilic yeasts. Since the 1950s,many studies have focused on mechanism of glycerol accumulation under high osmotic stress. Osmotic stress can be adjusted by adding carbohydrates or noncarbohydrates including amino acids, organic acids and inorganic salts into the medium. Inorganic salts have been studied most among the above mentioned osmoregulators. The application of glycerol find more important in the field of Cosmetics and Toiletries, Pharmaceuticals, Industrial Applications, Also it acts as an important raw material for new industrial fermentations in the future and its importance cannot be underestimated.

\section{Materials and Methods Microorganism \\ Candida krusei was used for the work. It was regenerated from its lyophilized culture purchased from microbial type cultural collection center, Chandigarh. The culture was maintained in agar slants.}

\section{Preculturing conditions}

Candida krusei was first grown in agar slants which have the following composition in $(\mathrm{g} / \mathrm{L})$ : Malt extract 3.0, Yeast extract 3.0, Glucose 40.0, Peptone 5.0 and Agar 20.0
The production medium consists of glucose, yeast extract and urea. The concentration of urea was held constant at $1.1 \mathrm{~g} / \mathrm{L}$ and concentration of glucose and yeast extract were varied by maintaining the yeast extract to glucose ratio constant at 1 part yeast extract per 20 parts glucose. All media used in this experiment were sterilized by autoclave at $121^{\circ} \mathrm{C}$ and $14.5 \mathrm{psi}$ for 15 minutes.

For the preparation of inoculum, cells from a freshly prepared slant were transferred aseptically to $500 \mathrm{ml}$ Erlenmeyer flask containing $100 \mathrm{ml}$ of sterile medium with a glucose concentration of $200 \mathrm{~g} / \mathrm{L}$. The flasks were incubated in a rotary shaker at $250 \mathrm{rpm}$ and at $30^{\circ} \mathrm{C}$. The overnight grown cultures were used for inoculating the production medium in shake flasks at 1:10 volume ratio.

\section{Analytical Techniques Estimation of cell growth}

Estimation of cell growth is carried out by spectrophotometric method. The optical density of all cultures is measured using spectronic-20D spectrophotometer at $600 \mathrm{~nm}$ with blanks of appropriate growth medium. Suspensions with an OD above 1.0 are diluted with the appropriate growth medium. Curves relating OD to dry weight are constructed by harvesting culture at room temp, washing with distilled water and resuspending the cells in distilled water to about $10 \mathrm{mg}$ of dry wt per $100 \mathrm{ml}$ portions $(50 \mathrm{ml})$ are centrifuged ay $10000 \mathrm{rpm}$ and dried at $70^{\circ} \mathrm{C}$ and weighed. The dry wt of the cells are determined. Candida krusie produces an extra cellular slime and in turn produces turbid solution. In such cases, OD is read against the culture supernatant blank, diluting the blank in the same ratio as the culture.

Test for total reducing sugars by DNS method The sample was suitably diluted to a conc. of 0.2 to $1.5 \mathrm{mg} / \mathrm{L}$. To $1 \mathrm{ml}$ of the sample $3 \mathrm{ml}$ of DNS 
was added, heated in boiling water bath for five minutes, cooled and diluted to $20 \mathrm{ml}$. The absorbance of the sample was then noted at 540 $\mathrm{nm}$ using spectrophotometer. Glucose standard was estimated from standard graph prepared from the standard glucose solution in the range of 0.2 to $2.0 \mathrm{mg} / \mathrm{L}$.

\section{Test for total polyols by Chromo tropic acid method}

Candida krusei consumes glucose and produce glycerol and trace amt of arabitol and erythritol. Chromo tropic acid method is used to test the total amt of polyols present in the test sample. In this method the interference of glucose is corrected by multiplying the glucose concentration by the factor of 0.03 and subtracting from the polyols concentration obtained. This will give the total and actual polyol conc.

\section{Procedure}

$2.0 \mathrm{ml}$ of the test solution containing 20-100 $\mu \mathrm{g} / \mathrm{ml}$ was taken in a test tube and $0.1 \mathrm{~N}$ sulphuric acid added

$0.5 \mathrm{ml}$ sodium periodates was added and incubated for five minutes followed by the addition of $0.5 \mathrm{ml}$ sodium arsenite.

The mixture was kept for 10-15 minutes and the volume was made up to $10 \mathrm{ml}$ by adding $6.9 \mathrm{ml}$ of distilled water.

$1.0 \mathrm{ml}$ of the solution was added to the $10 \mathrm{ml}$ of Chromotropic acid reagent, and heated in boiling water bath for 30 minutes.

The mixture was cooled and the absorbance was read at 570nm.

\section{Results and Discussion Effect of initial ph on the growth of Candida Krusei}

The effect of initial $\mathrm{pH}$ on cell growth and glycerol production using Candida krusei was studied by conducting experiments for $72 \mathrm{~h}$ at various initial $\mathrm{pH}$ levels ranging from 5.0-9.0. The optimum $\mathrm{pH}$ for cell growth and glycerol production was found to be 7.0 because it gave a maximum growth and yield of glycerol. The results are shown in following table 1 and figure 1. The growth of Candida krusei reaches maximum at $72 \mathrm{~h}$ of fermentation after that it falls down but for glycerol production gradual increase in production with respect to fermentation time was observed. The glycerol yield at $\mathrm{pH}$ 5.0-9.0 was found to be 0.38 and $0.35 \mathrm{gm} / \mathrm{L}$, respectively which were 70 and $60 \%$ of optimum value of $\mathrm{pH}$ $7.0(0.8 \mathrm{gm} / \mathrm{L})$. A low production of glycerol was obtained in acidic and alkaline $\mathrm{pH}$ values compared to neutral $\mathrm{pH}$, may be due to a lower metabolic activity of the organisms.
Table1: Effect of Initial $\mathrm{pH}$ on the growth and production of Glycerol by Candida krusei

\begin{tabular}{|c|c|c|}
\hline $\mathrm{pH}$ & $\begin{array}{l}\text { Cell mass } \\
\text { OD } \\
600 \mathrm{~nm}\end{array}$ & Glycerol \\
\hline 5 & 0.51 & 0.38 \\
\hline 5.5 & 0.55 & 0.388 \\
\hline 6 & 0.61 & 0.401 \\
\hline 6.5 & 0.65 & 0.41 \\
\hline 7 & 0.71 & 0.428 \\
\hline 7.5 & 0.61 & 0.41 \\
\hline 8 & 0.562 & 0.392 \\
\hline 8.5 & 0.478 & 0.372 \\
\hline 9 & 0.312 & 0.35 \\
\hline
\end{tabular}

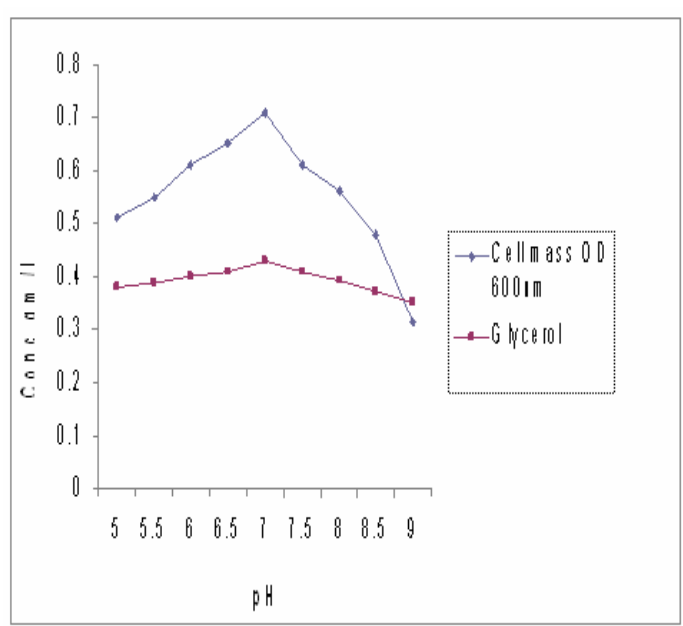

Fig. 1- Effect of Initial $\mathrm{pH}$ on the growth and production of Glycerol by Candida krusei

\section{Effect of fermentation time on biosynthesis of glycerol in batch culture}

The effect of fermentation time on biosynthesis of glycerol from Candida krusei utilizing glucose is studied by conduction batch experimental at various time intervals at $8,6,24,32,40,48,56,64$, and $72 \mathrm{~h}$ at glucose conc. of $20 \%$ by keeping all other parameters at constant level. The composition culture medium is same as the previous experiment. The results are shown in following table 2. and fig 2 the production of cell mass and glycerol steadily increases with increasing fermentation time. Fermentation time of $48 \mathrm{~h}$ is to be the optimum time for cell growth since the growth starts to decrease. Similarly for glycerol it is $56 \mathrm{~h}$. Even though the conc. of cell mass and glycerol are maximum at the end of $72 \mathrm{~h}$ the productivity will be lower, it is better to stop the fermentation either at 48 or $56 \mathrm{~h}$. 
Table 2- Effect of fermentation time on biosynthesis of Glycerol in batch culture Inoculum size: $10 \%(\mathrm{v} / \mathrm{v})$

Initial glucose concentration: $200 \mathrm{~g} / \mathrm{L}$

Temperature : $35^{\circ} \mathrm{C} \mathrm{pH}: 7.0$

\begin{tabular}{|r|r|r|}
\hline Time(hrs) & \multicolumn{1}{|l|}{$\begin{array}{l}\text { Cell mass } \\
\text { OD } \\
600 \mathrm{~nm}\end{array}$} & Polyol(g/L) \\
\hline 8 & 0.348 & 0.081 \\
\hline 16 & 0.412 & 0.128 \\
\hline 24 & 0.498 & 0.194 \\
\hline 32 & 0.54 & 0.276 \\
\hline 40 & 0.597 & 0.312 \\
\hline 48 & 0.647 & 0.391 \\
\hline 56 & 0.712 & 0.48 \\
\hline 64 & 0.87 & 0.54 \\
\hline 72 & 0.92 & 0.58 \\
\hline
\end{tabular}

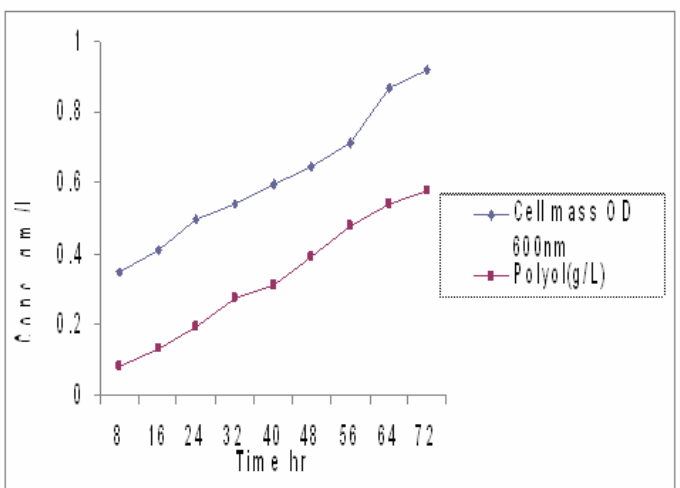

Fig. 2- Effect of fermentation time on biosynthesis of Glycerol in batch culture

Effect of initial substrate (glucose) concentration on glycerol in batch culture

The effect of initial substrate concentration on glycerol production using Candida krusei is studied by conducting the experiment at different substrate concentrations

of $15 \%, 17.5 \%, 20 \%, 22.5 \%$ and $25 \%(\mathrm{w} / \mathrm{v})$ for a fermentation time of 48 hours. The initial $\mathrm{pH}$ is kept at an optimum level of 7.0 with the inoculum size $10 \%(\mathrm{v} / \mathrm{v})$ the experiment of carried out in shake flasks in a shake (250 rpm). The medium compositions are same which are used in the previous expect the glucose conc. study. The time course of cell growth and polyol production are analyzed and results are shown in following tables 3.1 to 3.5 and fig.3.1 to 3.5. The substrate conc. is increased from $15 \%$ to $25 \%$, the concentration of cell mass and glycerol are increases considerably. The maximum conc. cell mass (0.920 OD) and glycerol $(0.720 \mathrm{~g} / \mathrm{L})$ are produced at $20.0 \%$ of glucose. At higher substrate concentrations levels, the cell mass and glycerol concentration decreases, this may be due to the substrate inhibition.
Table 3- Effect of Initial substrate (glucose) concentration $[15 \%(\mathrm{w} / \mathrm{v})]$ Production in batch culture

Inoculum size: $10 \%(\mathrm{v} / \mathrm{v})$

Initial glucose concentration: $150 \mathrm{~g} / \mathrm{L}$

Temperature : $35^{\circ} \mathrm{C} \mathrm{pH}: 7.0$

\begin{tabular}{|r|r|r|}
\hline Time(hrs) & \multicolumn{1}{|l|}{$\begin{array}{l}\text { Cell mass } \\
\text { OD } \\
\text { 600nm }\end{array}$} & Polyol(g/L) \\
\hline 8 & 0.148 & 0.072 \\
\hline 16 & 0.198 & 0.102 \\
\hline 24 & 0.278 & 0.17 \\
\hline 32 & 0.312 & 0.248 \\
\hline 40 & 0.398 & 0.292 \\
\hline 48 & 0.406 & 0.317 \\
\hline 56 & 0.51 & 0.391 \\
\hline 64 & 0.587 & 0.428 \\
\hline 72 & 0.612 & 0.49 \\
\hline
\end{tabular}

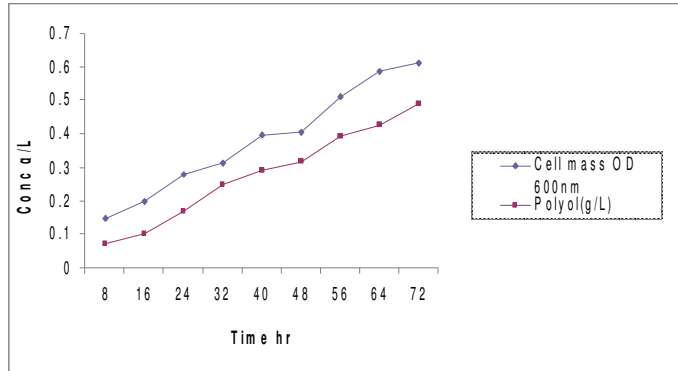

Fig. 3- Effect of Initial substrate (glucose) concentration [15\%(w/v)] on Glycerol production in batch culture

Table 4- Effect of Initial substrate (glucose) concentration $[17.5 \%(\mathrm{w} / \mathrm{v})]$ on Glycerol production in batch culture Inoculum size: $10 \%(\mathrm{v} / \mathrm{v})$ Initial glucose concentration: $175 \mathrm{~g} / \mathrm{L}$

Temperature : $35^{\circ} \mathrm{C} \quad \mathrm{pH}: 7.0$

\begin{tabular}{|r|r|r|}
\hline Time(hrs) & \multicolumn{1}{|l|}{$\begin{array}{l}\text { Cell mass } \\
\text { OD } \\
600 \mathrm{~nm}\end{array}$} & Polyol(g/L) \\
\hline 8 & 0.184 & 0.074 \\
\hline 16 & 0.241 & 0.112 \\
\hline 24 & 0.302 & 0.181 \\
\hline 32 & 0.384 & 0.26 \\
\hline 40 & 0.428 & 0.301 \\
\hline 48 & 0.507 & 0.304 \\
\hline 56 & 0.508 & 0.41 \\
\hline 64 & 0.612 & 0.456 \\
\hline 72 & 0.687 & 0.51 \\
\hline
\end{tabular}




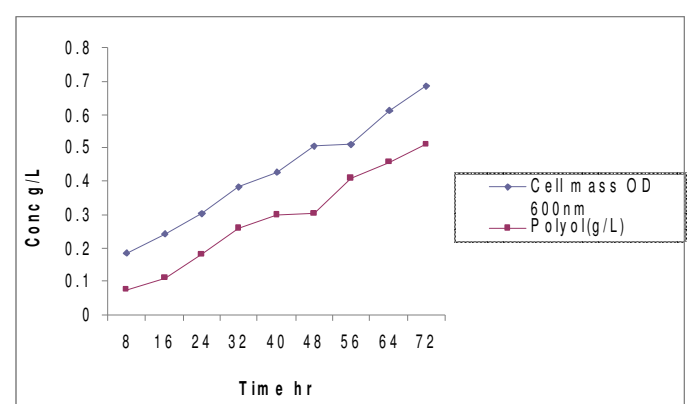

Fig. 4-Effect of Initial substrate (glucose) concentration $[17.5 \%(\mathrm{w} / \mathrm{v})]$ on Glycerol production in batch culture

Table 5- Effect of Initial substrate (glucose) concentration $[20 \%(\mathrm{w} / \mathrm{v})]$ on Glycerol production in batch culture

Inoculum size: $10 \%(\mathrm{v} / \mathrm{v})$

Initial glucose concentration: $200 \mathrm{~g} / \mathrm{L}$

Temperature : $35^{\circ} \mathrm{C} \mathrm{pH}: 7.0$

\begin{tabular}{|r|r|r|}
\hline Time(hrs) & $\begin{array}{l}\text { Cell mass } \\
\text { OD } \\
\text { 600nm }\end{array}$ & Polyol(g/L) \\
\hline 8 & 0.348 & 0.081 \\
\hline 16 & 0.412 & 0.128 \\
\hline 24 & 0.498 & 0.194 \\
\hline 32 & 0.54 & 0.276 \\
\hline 40 & 0.597 & 0.312 \\
\hline 48 & 0.647 & 0.391 \\
\hline 56 & 0.712 & 0.48 \\
\hline 64 & 0.87 & 0.54 \\
\hline 72 & 0.92 & 0.58 \\
\hline
\end{tabular}

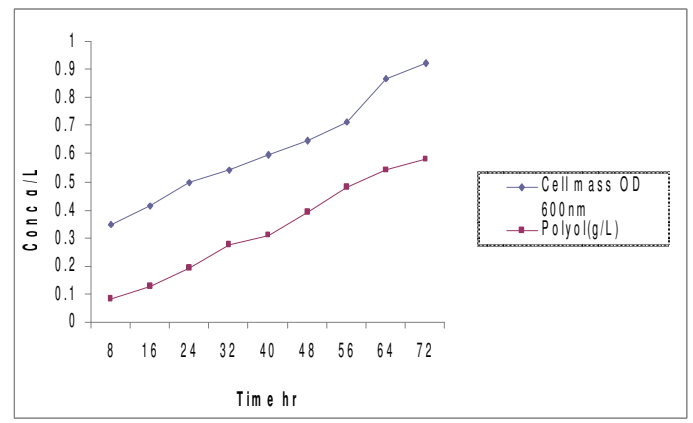

Fig. 5- Effect of Initial substrate (glucose) concentration $[20 \%(\mathrm{w} / \mathrm{v})]$ on Glycerol production in batch culture

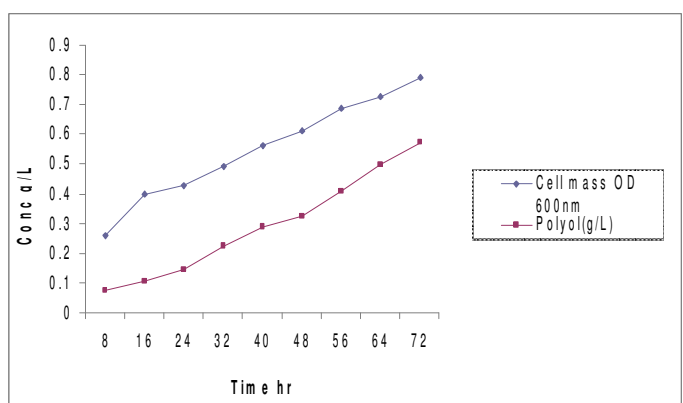

Fig. 6-Effect of Initial substrate (glucose) concentration $[22.5 \%(\mathrm{w} / \mathrm{v})]$ on Glycerol production in batch culture

Table 6- Effect of Initial substrate (glucose) concentration $[22.5 \%(\mathrm{w} / \mathrm{v})]$ on Glycerol production in batch culture Inoculum size: $10 \%(\mathrm{v} / \mathrm{v})$ Initial glucose concentration: $225 \mathrm{~g} / \mathrm{L}$ Temperature : $35^{\circ} \mathrm{C} \mathrm{pH}: 7.0$

\begin{tabular}{|r|r|r|}
\hline Time(hrs) & \multicolumn{1}{|l|}{$\begin{array}{l}\text { Cell mass } \\
\text { OD } \\
600 \mathrm{~nm}\end{array}$} & Polyol(g/L) \\
\hline 8 & 0.26 & 0.076 \\
\hline 16 & 0.396 & 0.102 \\
\hline 24 & 0.428 & 0.142 \\
\hline 32 & 0.49 & 0.224 \\
\hline 40 & 0.562 & 0.287 \\
\hline 48 & 0.612 & 0.322 \\
\hline 56 & 0.687 & 0.41 \\
\hline 64 & 0.728 & 0.498 \\
\hline 72 & 0.792 & 0.57 \\
\hline
\end{tabular}

Table 7- Effect of Initial substrate (glucose) concentration [25\%(w/v)] on Glycerol production in batch culture Inoculum size: $10 \%$ (v/v) Initial glucose concentration: $250 \mathrm{~g} / \mathrm{L}$ Temperature : $35^{\circ} \mathrm{C} \mathrm{pH}: 7.0$

\begin{tabular}{|r|r|r|}
\hline Time(hrs) & $\begin{array}{l}\text { Cell mass } \\
\text { OD } \\
600 n m\end{array}$ & Polyol(g/L) \\
\hline 8 & 0.24 & 0.068 \\
\hline 16 & 0.374 & 0.092 \\
\hline 24 & 0.401 & 0.112 \\
\hline 32 & 0.448 & 0.198 \\
\hline 40 & 0.51 & 0.24 \\
\hline 48 & 0.59 & 0.287 \\
\hline 56 & 0.64 & 0.328 \\
\hline 64 & 0.704 & 0.394 \\
\hline 72 & 0.728 & 0.468 \\
\hline
\end{tabular}




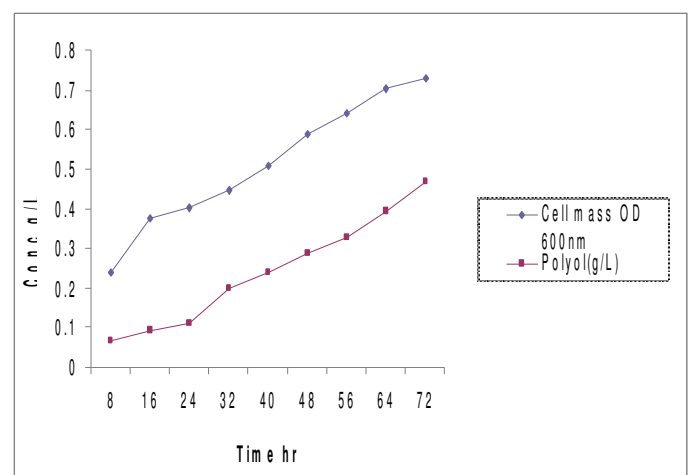

Fig. 7-Effect of Initial substrate (glucose) concentration [25\%(w/v)] on Glycerol production in batch culture

\section{Conclusion}

Glycerol synthesis using Candida krusei in a batch reactor were studied. Initial $\mathrm{pH} 7.0$ was found to be an optimum initial $\mathrm{pH}$ for Candida krusei where the maximum cell mass concentration was obtained. It was observed that the uptake capacity of Candida krusei show its maximum when the glucose is used as a carbon source maximum cell mass (0.920 OD) and glycerol conc. $(0.58 \mathrm{~g} / \mathrm{L})$ are obtained. Effect of mixed substrate on Candida krusei glycerol fermentation is not in significant level. The kinetic parameter values were estimated for Candida krusei fermentation. The Monod model and Monod incorporated Leudeking-Piret model where found followed closely to be experimental data for the growth and product formation kinetics respectively.

\section{References}

[1] Agarwal G.P. (1990) Glycerol, Advances in Biochemical engg, And Biotechnolgy,41.

[2] Ben-Amotz A. and Avron, M. (1980) In "Algal Biomass: Production and use", Ed.By Shelef, G. and soedar, C.J., Elsevier, Amesterdam,603.

[3] Hong-Juan Liu, De- Hua Liu, Jian - Zhong (2004) In : Oxygen limitation improves glycerol production by Candida krusei in a bioreactor, Elsevier,1899-1902.

[4] Hajny G.J. (1964) Appl.Microbiol.,12,87.

[5] Hajny G.J., Handershot, W.F. and Peterson, W.H. (1964) Appli microbial., 12,240.

[6] Mohammad J.Taherzadeh, Lennart Alder, Gunnar Liden (2002) In 'Strategies for enhancing fermentative production of glycerol-a review', Elsevier,53-66.

[7] Neish A.C.et.al. (1947) US patent 2,432,032.

[8] Newman A.A. (1968) In "Glycerol" MorganGrampian,London, 155.

[9] Nickerson W.J. and Carool W.R. (1945) Arch.Biochem,257.

[10] Onishi H., Bull Agri.chem.soc.Japn,25,124.
[11] Sahoo D.K and Agarwal.G.P (2001) In 'An investigation in glycerol biosynthesis by an osmophilic yeast in a bioreactor', Elsevier,839-846.

[12] Sols, A., Gancedo.C. and De La Fuenta G. (1971-2) by Rose, A.H. and Harrison, J.S., Acdemic prss London, 271.

[13] Spencer, J.F.T. and Gorin, P.A.J., (1960) Canadian J.Biochem.Physiol.,330,157.

[14] Spencer, J.F.T. and Sallins H.R. (1956) Canadian J.Microbiol.,2,72.

[15] Spencer,J.F.T. and shu, P. (1957) Canadian J.Microbiol.,3,559.

[16] Zheng-Xiang Wang,Jian Zhuge, Huiying Fang, Bernard A.Prior (2001) In 'Glycerol production by microbial fermentation: A review', Elsevier,201223. 